\title{
PROXIMITY COUPLED RECTANGULAR MICROSTRIP PATCH ANTENNA FOR S-BAND APPLICATIONS
}

\author{
Dinesh B Ganure ${ }^{1}$, S L Mallikarjun ${ }^{2}$, P M Hadalgi ${ }^{3}$, P V Hunagund ${ }^{4}$ \\ ${ }^{1}$ Research Scholar, Dept. of Applied Electronics, Gulbarga University, Kalaburagi, Karnataka, India \\ ${ }^{2}$ Guest Lecturer, Dept. of Applied Electronics, Gulbarga University, Kalaburagi, Karnataka, India \\ ${ }^{3}$ Professor, Dept. of Applied Electronics, Gulbarga University, Kalaburagi, Karnataka, India \\ ${ }^{4}$ Professor, Dept. of Applied Electronics, Gulbarga University, Kalaburagi, Karnataka, India
}

\begin{abstract}
Microstrip antennas have been one of the most featuring topic in antenna theory and design in recent years, and are progressively more finding application in a wide range of modern communication systems. In this study a microstrip antenna has been designed using proximity coupled feeding technique. The proposed antenna uses two layered substrate, such as the patch antenna on upper layer and the microstrip feedline on the lower layer. The study is made using the thickness of the substrate material. The experimental result shows that the Proximity coupled Rectangular Microstrip Antenna (PRMSA) gives an impedance bandwidth of $3.97 \%(110 \mathrm{MHz})$ and $17.17 \%$ of gain. Also the other antenna parameters such as radiation pattern, reflection coefficient, VSWR and HPBW are calculated and discussed.
\end{abstract}

Keywords: Rectangular microstrip patch, proximity feed, impedance bandwidth, gain.

\section{INTRODUCTION}

In the present day's communication, antennas cover a very large range of applications in various areas, like mobile communication, internet services, satellite navigation, automobiles and radars. Particularly, they are applied to microstrip antennas, due to its characteristics like low profile, lightweight and low power handling capacity [1-4]. Though, bandwidth and gain are sometimes low and not sufficient in most of applications. Alteration of shape and using special materials could be useful to solve such backlashes of this type of antennas. WiMAX (Wireless Interoperability for Microwave Access) is one of the latest wireless technologies. This technology can be used in numerous numbers of applications: the broadband services such as Voice over IP (VOIP), portable mobile connectivity, Digital Subscriber Line (DSL), etc [5].

Basically a microstrip antenna consists of a planar radiating design of desired geometrical shape on one side of a dielectric substrate material and a ground plane on the other. Generally preferred microstrip radiating geometries are rectangular and circular [6]. Still, other shapes are also considered depending upon the applications.

To connect power to a microstrip antenna is as important as the selection of a suitable geometry for a particular application. There are different types of feeding mechanisms are available and some vital among them are Microstrip feed, Co-axial feed, Aperture coupling feed and Proximity coupling feed. The Proximity coupling feed technique is used for the proposed microstrip antenna. It uses a two layer substrate with the patch antenna on the upper layer and the microstripline feed on the lower layer. The feed line finishes in an open end underneath the patch [6].

\section{ANTENNA DESIGN}

The Proximity-coupled Rectangular Microstrip Antenna (PRMSA) is fabricated with a commercially obtainable low cost glass epoxy substrate material with relative permittivity $\varepsilon \mathrm{r}=4.2$ and dielectric loss tangent $\tan \delta=0.02$.

Figure 1 shows the top view geometry of PRMSA. It consists of a length $\mathrm{L}$ and width $\mathrm{W}$ is etched on upper top surface of substrate $\mathrm{S}_{1}$. And the length $\mathrm{L}_{\mathrm{f}}$ and width $\mathrm{W}_{\mathrm{f}}$ of microstripline feed is etched on the upper top surface of substrate $S_{2}$. Thus the substrate $S_{2}$ is situated beneath substrate $S_{1}$ and the bottom surface of the substrate $S_{2}$ performs as the ground plane.

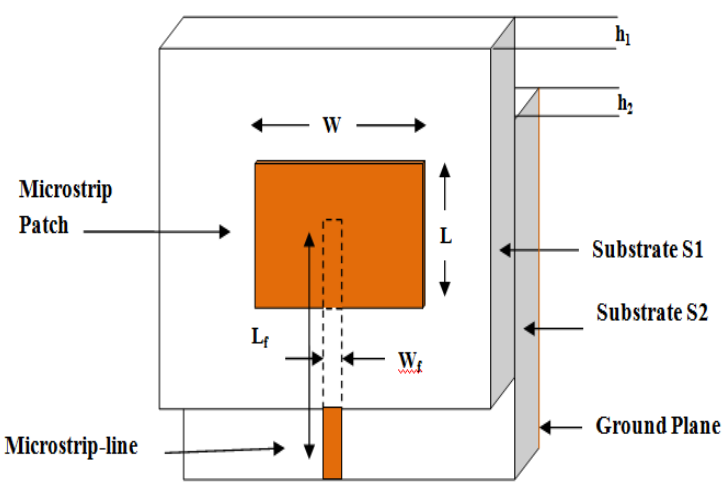

Fig -1: Geometry of PRMSA

The PRMSA has been designed for $3 \mathrm{GHz}$. The physical dimension of rectangular radiating patch and feedline are approximately determined from equations [1] and the dimensions are presented in the Table-1. 
Table -1: Designed parameters of proposed antenna

\begin{tabular}{|l|l|}
\hline $\begin{array}{l}\text { Antenna Geometry } \\
\text { Parameters }\end{array}$ & Dimensions \\
\hline Length of the patch, $\mathrm{L}$ & $24.34 \mathrm{~mm}$ \\
\hline Width of the patch, $\mathrm{W}$ & $31.00 \mathrm{~mm}$ \\
\hline Length of feedline, $\mathrm{L}_{\mathrm{f}}$ & $12.86 \mathrm{~mm}$ \\
\hline Width of feedline, $\mathrm{W}_{\mathrm{f}}$ & $6.33 \mathrm{~mm}$ \\
\hline Thickness of the substrate & $\mathrm{S} 1=3.2 \mathrm{~mm}$ \\
$\mathrm{~S} 2=1.6 \mathrm{~mm}$
\end{tabular}

\section{EXPERIMENTAL RESULTS}

The measurements are taken on Vector Network Analyzer ( $\{$ VNA $\}$ Rohde \& Schwarz, German make ZVK Model No. 1127.8651). The deviation of return loss versus frequency of PRMSA with thickness of substrates $\mathrm{S} 1=3.2 \mathrm{~mm} \mathrm{\&}$ $\mathrm{S} 2=1.6 \mathrm{~mm}$ by keeping the same permittivity which is shown in Figure 2. The impedance bandwidth over return loss less than $-10 \mathrm{~dB}$ is measured. The experimental impedance bandwidth is defined as,

$$
\text { Impedance Bandwidth }(\%)=\left[\frac{\mathrm{f}_{\mathrm{H}}-\mathrm{f}_{\mathrm{L}}}{\mathrm{f}_{\mathrm{C}}}\right] \times 100
$$

Where, $f_{H}$ is the higher cutoff frequency and $f_{L}$ is the lower cutoff frequency and $f_{C}$ is central frequency of the bands.

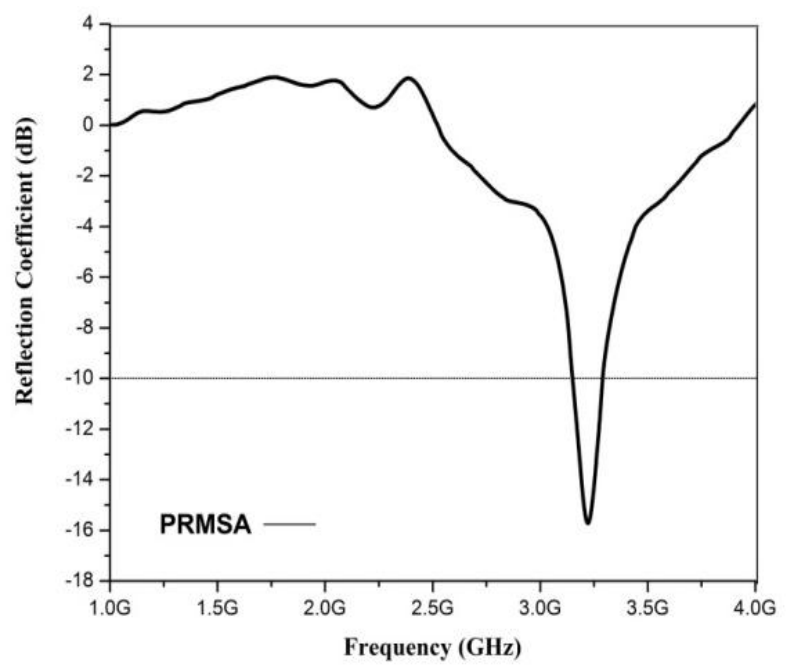

Fig -2: Deviation of Return loss Vs Frequency of PRMSA

As of the figure is observed, PRMSA with Substrate height $(\mathrm{S} 1=3.2 \mathrm{~mm} \& \mathrm{~S} 2=1.6 \mathrm{~mm})$ operates at $2.76 \mathrm{GHz}$ and impedance bandwidth is found to be $110 \mathrm{MHz}(\mathbf{3 . 9 7 \%})$, which is 1.22 times more when compared with the antenna with Substrate height $(\mathrm{S} 1=1.6 \mathrm{~mm} \mathrm{\&} \mathrm{S2}=1.6 \mathrm{~mm})$. Further, the minimum return loss measured in this antenna is $-15.75 \mathrm{~dB}$.

The co-polar and cross-polar radiation pattern of PRSMA is measured at X-Y plane at their resonating frequency and is depicted in Figure 3. The figure indicates that the antenna shows broader side radiation characteristic. The crosspolarization level of this antenna is found to be minimum which is below $-11 \mathrm{~dB}$ as shown.

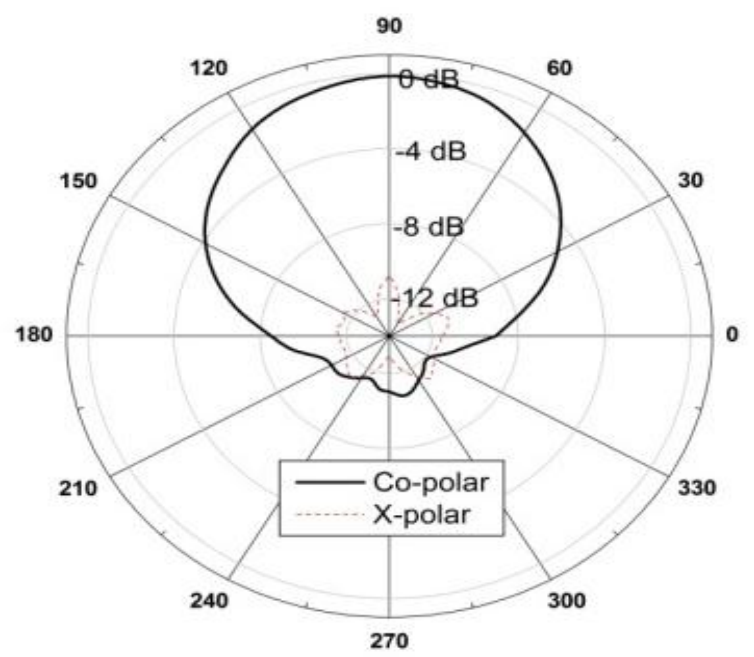

Fig -3: Radiation pattern at $2.76 \mathrm{GHz}$

The half power beam width (HPBW) for the proposed antenna is calculated for their resonating frequency and is also shown in Table 2 .

The gain of proposed antenna is calculated with fixed gain method given by the equation, [6]

$$
G(d B)=10 \log \left(\frac{P_{r}}{P_{t}}\right)-(G t) d B-20 \log \left(\frac{\lambda_{0}}{4 \pi R}\right) d B \ldots
$$

Where, $\mathrm{Pr}$ and $\mathrm{Pt}$ are received and transmitted powers respectively, $G t$ is the gain of the pyramidal horn antenna and $\mathrm{R}$ is the distance between antenna under test and transmitting antenna. The gain of the antenna is tabulated in Table 2.

Table -2: Calculated Min. cross polar, Gain, HPBW and VSWR

\begin{tabular}{|l|l|l|l|l|l|}
\hline $\begin{array}{l}\text { Substrate } \\
\text { Height }\end{array}$ & $\begin{array}{l}\text { Freq. } \\
\text { in } \\
\text { GHz }\end{array}$ & $\begin{array}{l}\text { Min. } \\
\text { Cross } \\
\text { polar } \\
\text { in dB }\end{array}$ & $\begin{array}{l}\text { Gain } \\
\text { in } \\
\text { dB }\end{array}$ & $\begin{array}{l}\text { HPBW } \\
\text { in } \\
\text { degrees }\end{array}$ & VSWR \\
\hline $\begin{array}{l}\text { S1 }=3.2 \mathrm{~mm} \\
\text { S2 }=1.6 \mathrm{~mm}\end{array}$ & 2.76 & -11 & 17.17 & $77^{0}$ & 1.81 \\
\hline
\end{tabular}

The antenna shows the input impedance which contains a loop at the middle of Smith chart which illustrates the matching of the feedline and radiating patch at $50 \Omega$ [7] which is shown in Figure 4. 


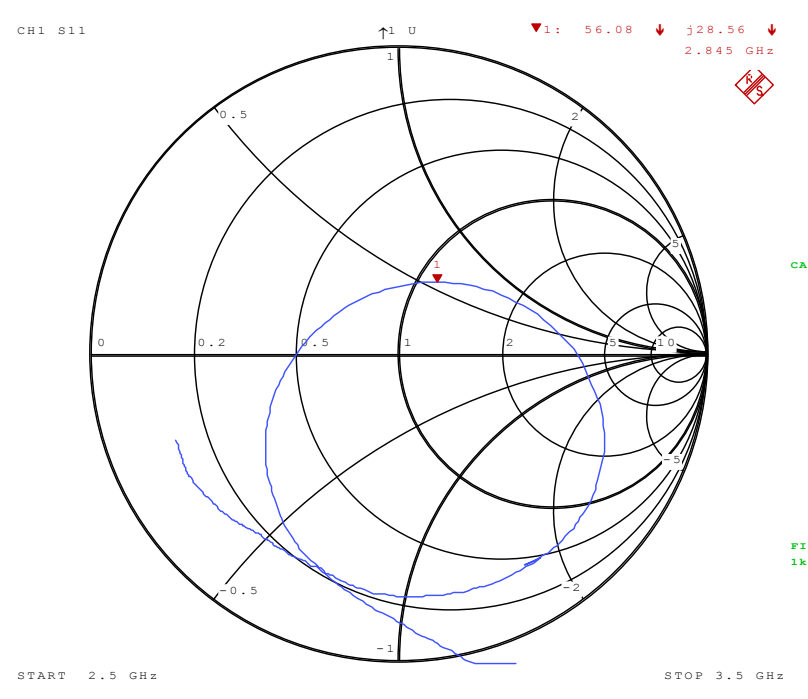

Fig -4: Smith chart profile

\section{CONCLUSION}

The entire experimental study illustrates that the antenna is relatively simple in design and fabrication and quite fine in enhancing the bandwidth and gives super broadside radiation pattern at the resonating frequency also the gain is found to be better as the thickness of antenna is increased. This antenna is also better as it uses low-priced substrate material and find the applications in S-band frequency range such as in modern wireless communication systems.

\section{ACKNOWLEDGMENTS}

The authors thank Department of Science and Technology (DST), GoI, New Delhi for sanctioning VNA to the Dept. of Applied Electronics, Gulbarga University, Kalaburagi.

\section{REFERENCES}

[1]. I. J. Bahl and P. Bhartia, Microstrip Antennas, Artech House, Dedham, MA, 1980.

[2]. Fan Yang; Xue-Xia Zhang; Xiaoning Ye; and YahyaRahmat-Samii, "Wide-Band E-Shaped Patch Antennas for Wireless Communications", IEEE Trans. Antennas Propog. Vol. 49, No. 7, 2001.

[3]. Girish Kumar and K. P. Ray, Broadband Microstrip Antennas, Norwood, MA: Artech House, 2003.

[4]. David M. Pozar, Microwave Engineering, Addison Wesley Publishing Company, Inc. 1990.

[5]. YahyaEntiefa Mansour, Single slot dual band microstrip antenna for WiMAX application, Atilim University, June 2014.

[6]. Ramesh Garg, Microstrip antenna design handbook, Artech House, Noorwood, MA, 2001.

[7]. S. L. Mallikarjun and P. M. Hadalgi, "Single layer modified rectangular microstrip array antenna for multi band and wide band applications", Indian Journal of Radio Physics, Vol. 39, pp.156-162, June 2010.

\section{BIOGRAPHIES}

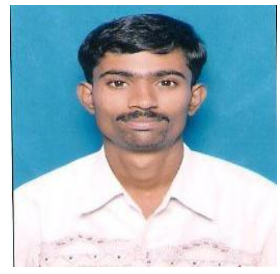

Mr. Dinesh B Ganure received his M.Sc., M.Phil degree in Applied Electronics from Gulbarga University, Gulbarga in the year 2010, 2013 respectively. $\mathrm{He}$ is working as a Research Scholar in Dept. of Applied Electronics, Gulbarga University, Gulbarga. He is an active researcher in the field of Microwave Electronics.

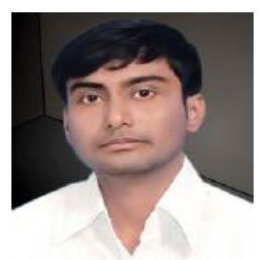

Dr. Mallikarjun S. L. received his M.Sc., M.Phil. and Ph.D. degree in Applied Electronics from Gulbarga University, Gulbarga in the year 2005, 2007 and 2011 respectively. $\mathrm{He}$ is working in Dept. of Applied Electronics, Gulbarga University, Gulbarga. He is an active researcher in the field of Microwave Electronics.

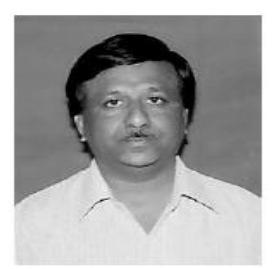

Dr. Hadalgi. P. M. Received his M.Sc., and Ph.D., degree in Electronics from Karnataka University, Dharwad. $\mathrm{He}$ is working as Professor in Dept. of Applied Electronics, Gulbarga University, Gulbarga. He is an active researcher in the field of Microwave Electronics. His area of interest includes waveguide antenna, microstrip antenna, DRA and instrumentation. He has more than 150 publications in reputed International/National Journals and in conference and symposia.

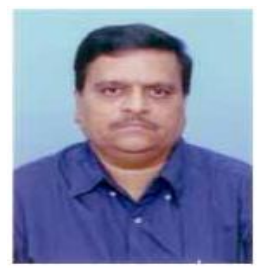

Dr. P. V. Hunagund received his M.Sc and Ph.D from the Dept. of Applied electronics, Gulbarga University, Gulbarga, in the year 1982 and 1992 respectively. He is working as professor and chairman of Applied Electronics department, Gulbarga University, Gulbarga. He has more than 100 research publications in national and international reputed journals, more than 200 research publications in international symposium/Conferences. He has guided many Ph.D and M.Phil students. 